\title{
Comparative Study of Weighted Product-Dijkstra's Algorithm and All Possible Path Approach Based on Multiple Criteria and Multi-Dimensions
}

\author{
Ting Kien Hua ${ }^{1}$ and Noraini Abdullah ${ }^{2 *}$ \\ ${ }^{1}$ Centre of Postgraduate Studies, Universiti Malaysia Sabah. \\ ${ }^{2}$ Faculty Science and Natural Resources, Universiti Malaysia Sabah.
}

\begin{abstract}
In this uncertain environment, most of the decision making involved multiple criteria and multidimension instead of single criterion or dimension. The focus of this paper was the decision making in choosing the best path within a network based on multiple criteria. Therefore, Weighted ProductDijkstra's Algorithm (WPDA) was introduced in this paper for optimal path identification with involvement of multiple criteria. It was a combined algorithm of Weighted Product Method (WPM) and Dijkstra's Algorithm. Weighted product method was one of the algorithms in Multi-Criteria Decision Making (MCDM) that was used to combine multiple criteria into new scores for further evaluation. Dijkstra's algorithm was one of the shortest path algorithms that would be used to identify the path with the least cost. All Possible Path Algorithm (APPA) was another algorithm that was also used to rank all the alternatives path based on multiple criteria. WPDA and APPA were reviewed and compared. WPDA can handle both single dimension and multi-dimension problems. Besides, it can identify the optimal path without consideration of all the possible alternatives. Overall, WPDA performed better compared to APPA in terms of efficiency and simplicity. In a larger scale network problem, Maple software can be used as a tool to ease the computation, instead of manually.
\end{abstract}

Keywords: Weighted Product-Dijkstra's Algorithm (WPDA), Combination, Multiple Criteria, MultiDimension, All Possible Path Algorithm (APPA)

\section{INTRODUCTION}

The emergence of new technology has changed the environment from time to time. Uncertainty and ambiguity of the future become one of the challenges for today's life. Problems nowadays are becoming complex especially those problems that are involved in business, management. Decision making can reduce the uncertainty and doubt about alternatives to allow a suitable and reasonable solution to a problem. Right decision making is an important issue to achieve a better performance.

The focus of the field was urban road traffic network problem. Decision making in choosing the best path for different purposes and preferences was carried out. Neumann (2014) said that shortest path was not the best path selection because it might not be when it comes to different condition. Road users will not only consider distance as the only criteria but cost, safety, time travel, road condition and so forth. The main objective of this study is to identify the best path for different time periods with consideration of multiple criteria.

In this study, a modified algorithm as called Weighted Product-Dijkstra's Algorithm (WPDA) in finding an optimal path with consideration of the multiple criteria. Weighted Product Method (WPM) was like Weighted Sum Method (WSM). WPM was widely applied in different fields and 
provided reasonable solution with involvement of multiple criteria (Setyawan et. al., 2017). They further stated that WPM provides more in-depth results than WSM. However, WPM might take longer execution time than WSM due to simplicity of WSM. Fitriasari et. al., (2017) performed a comparative analysis of WPM and Technique for Order Preference by Similarity to Ideal Solution (TOPSIS) Method in terms of complexity and accuracy. Overall, TOPSIS was much more complex than WPM but TOPSIS has higher accuracy level than WPM. Mateo (2012) mentioned that WPM has a major drawback that involved over values extremes which lead to undesirable results. Throughout the comparative study done by Gayatri \& Chetan (2013), it showed that WPM method can eliminate any unit of measure; therefore, it was applicable to single and multi-dimensional problems. WPM can ignore the transformation of different dimensional measurement units to same dimensional units by the normalization process (Odu\& Charles-Owaba, 2013). Tofallis (2014) performed a tutorial on ranking and choosing with consideration of multiple criteria. Overall, WPM was much more recommended since it can provide transparent interpretation for the weights and overcome re-scaling problem in WSM (Tofallis, 2014).

Nagar \& Taufik (2007) presented an approach in analyzing and prototyping urban road network routes based on multiple criteria to evaluate the quality of the road. The proposed approach was the combination algorithm of Dijkstra's algorithm and Weighted Sum Method. It determined the best path between two points based on the combination of distance, comfort and view criteria. Moreover, Roghanian \& Shakeri Kebria (2017) proposed a new method which was the combination of TOPSIS method and Dijkstra's algorithm in multi-attribute routing. Instead of WPM and Dijkstra's algorithm, a combined algorithm, Weighted Product-Dijkstra's Algorithm was suggested that would be similar to the study carried out by Roghanian \& Shakeri Kebria (2017), a combination of TOPSIS and Dijkstra's algorithm. Weighted Product Dijkstra's Algorithm (WPDA) was hence proposed. It was compared with All Possible Path Algorithm (APPA) in terms of simplicity and accuracy. APPA is a method that can rank the alternatives based on the cost (Mohammadi \& Hunter, 2012).

\section{DEFINITION OF NETWORK GRAPH}

Let $G=(V, E)$ be a graph in order to define the problem. A graph $G$ is formed by a collection of nodes and edges. A number assigned to the edges called weight that indicates the extent of connectivity of the arcs. Network graph is a set of vertices that consist of element $1,2, \ldots, n-1$ linked by edges. The nodes of the network graph are the elements of $V$ which denoted as $v_{1}, v_{2}, \ldots, v_{n-1}, v_{n} \in V$. The $v_{1}$ is the source (starting) node and $v_{n}$ is the sink (ending) node. The edges defined by the ordered pairs $(u, v)$. The edges $(u, v)$ are the element of $E$ over these nodes of the network graph. A graph is directed if there is an arrow that specified the direction of the arcs (Bose, 2012).

\section{DIJKSTRA'S ALGORITHM}

Dijkstra's algorithm is a shortest path algorithm that was founded by Edsger Wybe Dijkstra in 1956, and published three years later in 1959. The further definition and description for the algorithm are showed below.

Consider an $\operatorname{arc}(u, v)$ of cost $c_{u v}>0$. Let $L C_{u}$ is equal to lowest cost from node 1 to node $u$. The label of node $v$ connected with node $u$ is defined as the pair of elements $\left[L C_{v}, u\right]=\min _{u}\left[L C_{v}+c_{u v}, u\right]$. If there is only one $u$ connected to $v$, the right-hand side gives the label of $v$ and is said to be permanent. If there are several $u$ connected to $v$, the label $\left[L C_{u}+c_{u v}, u\right]$ for a permissible value of $u$ is called temporary, provided a shorter connection from some other acceptable value of $u$ can be found. If no shorter connection can be found, it is as before, called a permanent label. With these definitions, the method consists of the following algorithm:

i. $\quad$ Label starting node, $s$ with permanent label $[0,-]$. Set $v=1$.

ii. Compute temporary labels $\left[L C_{u}+c_{u v}, u\right]$ for each node $v$ that can be reached from node $u$. If node $v$ has already the label $\left[L C_{v}, w\right]$ through another node $w$ such that $L C_{u}+c_{u v}<L C_{v}$ then 
replace $\left[L C_{v} \cdot w\right]$ by $\left[L C_{u}+c_{u v}, u\right]$. Otherwise $\left[L C_{u}+\right.$ $\left.c_{u v}, u\right]$ is the permanent label of node $v$.

iii. For $v<n$, set $v=$ next $v$, reachable from permanently labeled nodes and Go to Step 2. $w$ stands for the adjacent node of $v$. If all the nodes have permanent labels and $v=n$, then Stop. (Bose, 2012).

\section{WEIGHTED SUM METHOD (WSM) AND WEIGHTED PRODUCT METHOD (WPM)}

Weighted Sum Method is a simple method which applicable to single dimensions problems. Additive utility hypothesis is applied in WSM.

$$
\mathrm{c}_{\mathrm{uv}}=\sum_{\mathrm{v}=1}^{\mathrm{y}} \mathrm{a}_{\mathrm{uv}} \mathrm{w}_{\mathrm{v}}, \forall \mathrm{v}=1, \ldots, \mathrm{y}
$$

WPM is a similar method to Weighted Sum Method (WSM). Instead of additive utility hypothesis, WPM applied multiplicative utility hypothesis. Each alternative is compared to the rest through a multiplication of ratios that are related to every criterion.

$$
\begin{gathered}
\mathrm{c}_{\mathrm{uv}}=\prod_{\mathrm{v}=1}^{\mathrm{y}} \mathrm{a}_{\mathrm{uv}} \mathrm{w}_{\mathrm{v}}, \forall \mathrm{v}=1, \ldots, \mathrm{y} . \\
\mathrm{c}_{\mathrm{uv}}=\text { overall score of the branches } \\
\mathrm{a}_{\mathrm{uv}}=\text { values for the branches according to } \\
\text { the criterion } \\
\mathrm{w}_{\mathrm{v}}=\text { weight for the criterion, } \mathrm{v} .
\end{gathered}
$$

\section{WEIGHTED PRODUCT-DIJKSTRA'S ALGORITHM (WPDA)}

Weighted Product- Dijkstra's Algorithm is a similar method in term of concept as compared to Dijkstra-based Weighted Sum Minimization (DWSM) algorithm (Kolios et. al., 2016). DWSM algorithm is an additive utility algorithm with combination of Dijkstra's algorithm, and Kolios et. al., (2016) applied it to minimize delay and maximize path for a non-static Wireless Mesh Network. However, WPDA is the combination method of multiplicative utility with Dijkstra's Algorithm. Below is the algorithm of the WPDA.

1. Presenting all the branches and criteria in matrix form as shown in equation (2) based on $x$ branches and $y$ criteria. The involved criterion that must be maximized should apply the inversion of the criterion, $1 / a^{x y}$ so that the path with the minimum criteria values can be identified.

$$
A=\left[\begin{array}{ccc}
a_{11} & \ldots & a_{1 y} \\
\ldots & \ldots & \ldots \\
a_{x 1} & \ldots & a_{x y}
\end{array}\right]
$$

2. Applying Weighted Product Method (WPM) as shown in equation (1) to multiply the relevant weight by matrix $\mathrm{A}$ and forming matrix $\mathrm{V}$ as shown in equation (3).

$$
V=\left[\begin{array}{ccc}
a_{11}{ }^{w_{1}} & \ldots & a_{1 y}{ }^{w_{y}} \\
\ldots & \ldots & \ldots \\
a_{x 1} w_{1} & \ldots & a_{x y}{ }^{w_{y}}
\end{array}\right]
$$

3. Forming the network graph according to the new cost value of the branches according to the matrix $\mathrm{V}$.

4. Solving the formed network graph by Dijkstra's algorithm to identify the optimal path which has the minimum distance value with consideration of multiple criteria.

\section{ALL POSSIBLE PATH ALGORITHM (APPA)}

1. APPA finds all possible paths that link from source node to sink node in a network graph.

2. Start with an iteration in which the database tries to find all edges that start with the source point.

3. Join those edges with all other edges for which the start point is equal to the end point of the current edge.

4. Iterate the process until the end point of the path is reached.

5. Compute the total value of each criterion for the identified possible paths.

6. Combine multiple criteria into a new cost value by Weighted Product Method.

7. Rank the possible paths according to new cost value(Mohammadi \& Hunter, 2012).

\section{FLOWCHART}

Figure 1 showed the flowchart of the WPDA and APPA in identifying the ranking and optimal path for a network problem. 


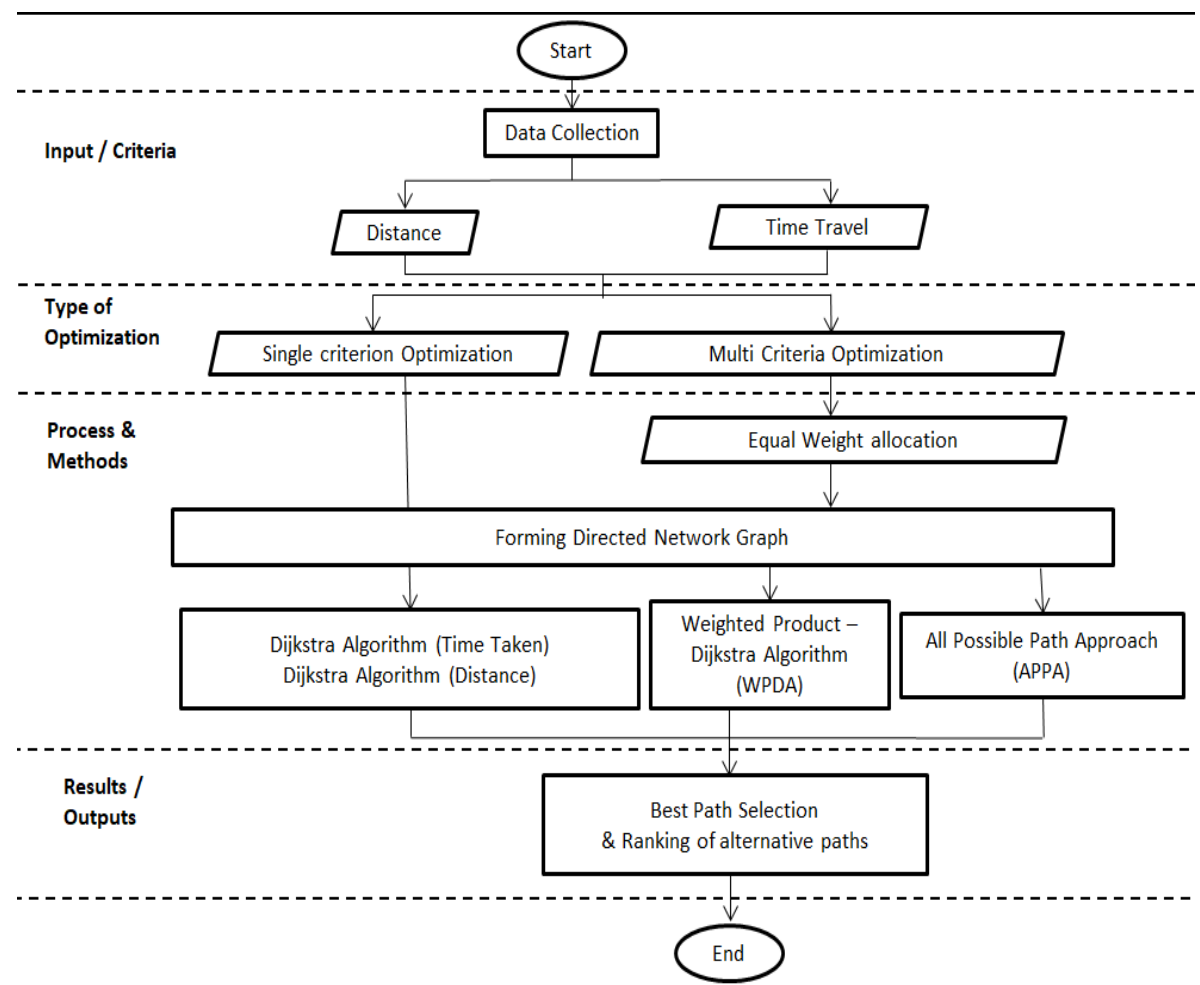

Figure 1: Flowchart Using WPDA \& APPA

First, it started with data collection. Next, the collected data with different parameters was used to form into network graph. Then, it was solved by Dijkstra's algorithm, Weighted Product-Dijkstra's Algorithm (WPDA) and All Possible Path
Algorithm (APPA) to get the best path with concerned of multiple criteria and the ranking of alternative paths, respectively.

\section{SCOPE OF STUDY}

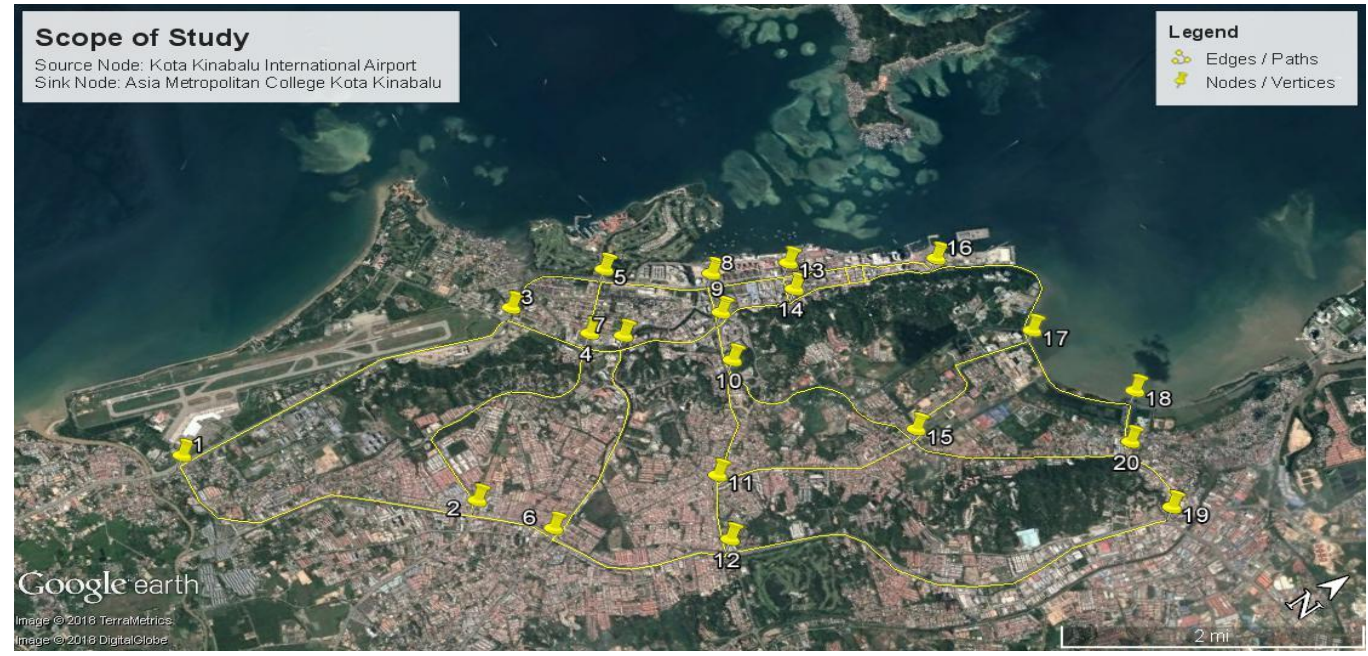

Figure 2: Scope of Study in Kota Kinabalu

Figure 2 showed the chosen scope of network in Kota Kinabalu as indicated by the yellow dots. The scope of this study is within in the city of Kota Kinabalu, Sabah, Malaysia. The severe congestion problem in Kota Kinabalu was due to the poor public transportation and abundance of vehicles that has caused road users to feel hatred while being stuck on road. 


\section{DATA COLLECTIONS}

Table 1 showed the average time travel and distance for different branches with connected nodes into a network graph. Four time periods, Morning, Afternoon, Evening and Midnight periods were displayed in Table 1.

Table 1: Collected Data for Average Time Travel

\begin{tabular}{|c|c|c|c|c|c|c|}
\hline \multirow[b]{2}{*}{$\begin{array}{c}\text { Fro } \\
\mathrm{m}\end{array}$} & \multirow[b]{2}{*}{ To } & \multirow{2}{*}{$\begin{array}{c}\text { Distance } \\
\text { (Kilomet } \\
\text { er) }\end{array}$} & \multicolumn{4}{|c|}{ Average Time Travel (Minutes) } \\
\hline & & & $\begin{array}{c}\text { Morni } \\
\text { ng }\end{array}$ & $\begin{array}{l}\text { After } \\
\text { noon }\end{array}$ & $\begin{array}{c}\text { Eveni } \\
\text { ng }\end{array}$ & $\begin{array}{c}\text { Midni } \\
\text { ght }\end{array}$ \\
\hline 1 & 2 & 3.6 & 4.75 & $4 \cdot 75$ & 6.25 & 4 \\
\hline 1 & 3 & 4 & 4.875 & 4 & 4 & 4 \\
\hline 3 & 5 & 1.4 & 2.25 & 2 & 1.75 & 1 \\
\hline 5 & 8 & 1.2 & 2.625 & $\begin{array}{c}4.62 \\
5\end{array}$ & $5 \cdot 5$ & 2 \\
\hline 8 & 13 & 0.8 & 2 & 4.375 & 3.125 & 2 \\
\hline 13 & 16 & 1.7 & 5.25 & 7.125 & 5.875 & 4 \\
\hline 16 & 17 & 2.1 & 2 & 3.125 & 5.25 & 2 \\
\hline 17 & 18 & 1.4 & 1.625 & 2 & 2 & 2 \\
\hline 2 & 6 & 0.9 & 5.25 & 2.125 & 2.25 & 2 \\
\hline 6 & 12 & 2 & 3 & 3 & 3 & 3 \\
\hline 12 & 19 & 5.1 & $5 \cdot 75$ & 5.875 & 7.125 & 5 \\
\hline 19 & 20 & 1 & 1.5 & 2.125 & 1.625 & 1 \\
\hline 18 & 20 & 0.6 & 1.875 & 2.75 & 3.625 & 1 \\
\hline 3 & 4 & 0.9 & 3.125 & 4 & 4.25 & 1 \\
\hline 4 & 3 & 0.9 & 1.875 & 1.625 & 1.625 & 1 \\
\hline 2 & 4 & 3.4 & 5.875 & $5 \cdot 75$ & 4.75 & 4 \\
\hline 4 & 2 & 3.4 & 4.375 & 5 & 6.875 & 4 \\
\hline 4 & 5 & 0.85 & 2 & 2 & 3.375 & 2 \\
\hline 5 & 4 & 0.85 & 2 & 3 & 3.875 & 2 \\
\hline 4 & 7 & 0.35 & 1 & 1 & 1 & 1 \\
\hline 7 & 4 & 0.35 & 1.5 & 2.5 & 1.875 & 1 \\
\hline 7 & 6 & 2.7 & 5.25 & 5 & 5.75 & 5 \\
\hline 6 & 7 & 2.7 & 6.125 & 6.125 & 5.625 & 5 \\
\hline 7 & 9 & 1.1 & 1.75 & 2 & 1.625 & 1 \\
\hline 9 & 7 & 1.1 & 2 & 4 & 4.5 & 1 \\
\hline 8 & 9 & 0.7 & 2 & 2.25 & 2.5 & 2 \\
\hline 9 & 8 & 0.7 & 1.5 & 1.375 & 1.5 & 1 \\
\hline 9 & 14 & 0.85 & 2.125 & $\begin{array}{c}2.87 \\
5\end{array}$ & 2.375 & 1 \\
\hline 14 & 9 & 0.85 & 2 & 2 & 2 & 1 \\
\hline 14 & 13 & 0.28 & 1 & 1.125 & 1.5 & 1 \\
\hline 14 & 16 & 1.6 & 4.375 & 4.125 & 4.375 & 3 \\
\hline 16 & 14 & 1.6 & 3.875 & 6.375 & 6 & 3 \\
\hline
\end{tabular}

\begin{tabular}{|c|c|c|c|c|c|c|}
\hline 9 & 10 & 0.75 & 1 & 1 & 1 & 1 \\
\hline 10 & 9 & 0.75 & 1 & 1 & 1 & 1 \\
\hline 10 & 11 & 1.4 & 2.375 & 2.125 & 4 & 2 \\
\hline 11 & 10 & 1.4 & 2 & 2 & 2 & 2 \\
\hline 11 & 12 & 0.85 & 2 & 2 & 2.375 & 1 \\
\hline 12 & 11 & 0.85 & 3.25 & 3.125 & 2.375 & 1 \\
\hline 10 & 15 & 2.3 & 3.25 & 5 & 3.25 & 3 \\
\hline 15 & 10 & 2.3 & 3 & 3 & 3 & 3 \\
\hline 11 & 15 & 2.3 & 4.25 & 4.125 & 4.125 & 3 \\
\hline 15 & 11 & & & 4.87 & & 4 \\
\hline 15 & 17 & 2.2 & 4 & 4.375 & 4.625 & 4 \\
\hline 17 & 15 & 2.2 & 4.75 & 7.375 & 5.375 & 4 \\
\hline 15 & 20 & 2.3 & 3.375 & 3.75 & 9.75 & 3 \\
\hline
\end{tabular}

Distance and time travel were collected through Google Map. Time travels for different branches were collected according to different time periods specifically for weekdays. The time travel for four different periods were collected which were weekday's peak hours for morning (7 am - $9 \mathrm{am}$ ), afternoon (12 pm - $2 \mathrm{pm})$ and evening ( $5 \mathrm{pm}-7 \mathrm{pm})$ and weekday's off-peak hour for midnight (12 pm - 2 am). The shortest path might not be the best path as encounter to the traffic congestion. Therefore, peak hour and off-peak hour were chosen in this study to find out which path fit to the particular time. Different peak hour will have different number of traffic flow condition. The off-peak hour period was chosen to find out which path is best fit for different peak hour. The purpose of collecting different time travel is to find out the suitable alternative paths for different time periods. The time travel for each branch was collected for every15 minutes time interval within two hours of the peak or offpeak period. The collected different time travels for 15 minutes interval was equally divided in order to obtain the average time travel for each branch.

\section{RESULTS OF DIJKSTRA ALGORITHM AND WPDA}

Table 3 and Table 4 showed the comparative results between WPDA and Dijkstra's algorithm solely. 
Table 3: Comparative Results of Using the Dijkstra's Algorithm solely

\begin{tabular}{|c|c|c|c|c|}
\hline \multicolumn{5}{|c|}{ Dijkstra's algorithm with each attribute } \\
\hline \multicolumn{4}{|c|}{ Time Travel } & \multirow[t]{2}{*}{ Distance } \\
\hline Morning & $\begin{array}{c}\text { Afternoo } \\
n\end{array}$ & Evening & $\begin{array}{c}\text { Midnigh } \\
\mathrm{t}\end{array}$ & \\
\hline $1-3-4-7-$ & $1-2-6-12-$ & $1-2-6-$ & $1-3-4-7-$ & $1-3-4-7-9-$ \\
\hline $9-10-15^{-}$ & $19-20$ & $12-19-20$ & $9-10-15^{-}$ & $10-15-20$ \\
\hline 20 & $(17.875$ & $(20.25$ & 20 & (11.7 \\
\hline$(18.375$ & minutes) & minutes & $(14$ & kilometers \\
\hline minutes & & ) & minutes & ) \\
\hline ) & & & ) & \\
\hline
\end{tabular}

Table 4: Comparative Results of the WPDA

\begin{tabular}{|c|c|c|c|c|}
\hline \multicolumn{5}{|c|}{ Weighted Product-Dijkstra's Algorithm (WPDA) } \\
\cline { 1 - 4 } & \multicolumn{3}{|c|}{ Time Travel } \\
\cline { 1 - 3 } Morning & Afternoo & Evening & Midnigh & \\
& $\mathrm{n}$ & & $\mathrm{t}$ & \\
\hline $1-3-4-7-$ & $1-3-4-7-9-$ & $1-2-6-$ & $1-3-4-7-$ & $1-3-4-7-9-$ \\
$9-10-15^{-}$ & $10-15-20$ & $12-19-20$ & $9-10-15^{-}$ & $10-15-20$ \\
20 & $(18.375$ & $(20.25$ & 20 & $(18.375$ \\
$(18.375$ & minutes, & minutes, & $(14$ & minutes ,11 \\
minutes & $11.7 \mathrm{~km})$ & $12.6 \mathrm{~km})$ & minutes, & $.7 \mathrm{~km})$ \\
,11.7km) & & & $11.7 \mathrm{~km})$ & \\
\hline
\end{tabular}

By using Dijkstra's algorithm only, $1 \rightarrow 3 \rightarrow 4 \rightarrow 7 \rightarrow 9 \rightarrow$ $10 \rightarrow 15 \rightarrow 20$ was the shortest time travel path for morning peak hour (18.375 minutes) and midnight off-peak hour (14 minutes). $1 \rightarrow 2 \rightarrow 6 \rightarrow 12 \rightarrow 19 \rightarrow 20$ was the shortest time travel path for afternoon (17.675 minutes) and evening peak hour (20.25 minutes). The shortest path, $1 \rightarrow 3 \rightarrow 4 \rightarrow 7 \rightarrow$ $9 \rightarrow 10 \rightarrow 15 \rightarrow 20$ with 11.7 kilometers was identified by Dijkstra algorithm. Weighted Product-Dijkstra's Algorithm (WPDA) identified the optimal path with consideration of more than one criterion. WPDA identified that $1 \rightarrow 3 \rightarrow 4 \rightarrow$ $7 \rightarrow 9 \rightarrow 10 \rightarrow 15 \rightarrow 20$ was the optimal path for morning peak hour and midnight off-peak hour and the path1 $\rightarrow 2 \rightarrow$ $6 \rightarrow 12 \rightarrow 19 \rightarrow 20$ was the optimal path for afternoon and evening peak hour period after consideration of both distance and time travel.

\section{XI.RESULTS OF APPA}

There were about 402 of possible paths that were identified. Among the 402 possible paths, the top 10 possible paths were displayed in Table 5. The total average time travel and total distance for the top 10 possible paths were calculated by summing up all the branches of the path.

Table 5: Total Average Time Travel and Total Distance of the Top 10 Possible Paths

\begin{tabular}{|c|c|c|c|c|c|}
\hline \multirow[b]{2}{*}{ Paths } & \multicolumn{4}{|c|}{$\begin{array}{l}\text { Total Average Time Travel } \\
\text { (Min) }\end{array}$} & \multirow{2}{*}{$\begin{array}{c}\text { Total } \\
\text { Distance } \\
(\mathrm{Km})\end{array}$} \\
\hline & $\begin{array}{l}\text { Mor } \\
\text { ning }\end{array}$ & $\begin{array}{l}\text { After } \\
\text { noon }\end{array}$ & $\begin{array}{l}\text { Eve } \\
\text { ning }\end{array}$ & $\begin{array}{c}\text { Mid } \\
\text { nigh } \\
t\end{array}$ & \\
\hline $\begin{array}{c}1-2-6-12- \\
19-20\end{array}$ & $\begin{array}{c}20.2 \\
5\end{array}$ & $\begin{array}{c}17.87 \\
5\end{array}$ & $\begin{array}{c}20.2 \\
5\end{array}$ & 15 & 12.6 \\
\hline $\begin{array}{l}1-2-6-12- \\
11-15-20\end{array}$ & $\begin{array}{c}23.8 \\
75\end{array}$ & $\begin{array}{c}20.8 \\
75\end{array}$ & $\begin{array}{c}27 \cdot 7 \\
5\end{array}$ & 16 & 11.95 \\
\hline $\begin{array}{l}1-2-4-7-6- \\
12-19-20\end{array}$ & $\begin{array}{c}27.1 \\
25\end{array}$ & 27.5 & 29.5 & 23 & 18.15 \\
\hline $\begin{array}{l}1-2-4-7-9- \\
10-15-20\end{array}$ & 21 & $\begin{array}{c}21.87 \\
5\end{array}$ & $\begin{array}{c}27.6 \\
25\end{array}$ & 17 & 13.8 \\
\hline $\begin{array}{l}1-3-5-8-9- \\
10-15-20\end{array}$ & $\begin{array}{c}19.3 \\
75\end{array}$ & 21.25 & $\begin{array}{c}27 \cdot 7 \\
5\end{array}$ & 16 & 12.65 \\
\hline $\begin{array}{l}1-3-4-2-6- \\
12-19-20\end{array}$ & $\begin{array}{c}27.8 \\
75\end{array}$ & $\begin{array}{c}26.12 \\
5\end{array}$ & $\begin{array}{c}29.1 \\
25\end{array}$ & 20 & 17.3 \\
\hline $\begin{array}{l}1-3-4-7-6- \\
12-19-20\end{array}$ & 24.5 & 25 & $\begin{array}{c}26.7 \\
5\end{array}$ & 20 & 16.05 \\
\hline $\begin{array}{l}1-3-4-7-9- \\
10-15-20\end{array}$ & $\begin{array}{c}18.3 \\
75\end{array}$ & $\begin{array}{c}19.37 \\
5\end{array}$ & $\begin{array}{c}24.8 \\
75\end{array}$ & 14 & 11.7 \\
\hline $\begin{array}{c}1-2-6-12- \\
11-10-15-20\end{array}$ & $\begin{array}{c}24.8 \\
75\end{array}$ & $\begin{array}{c}22.37 \\
5\end{array}$ & $\begin{array}{c}28.8 \\
75\end{array}$ & 18 & 13.35 \\
\hline $\begin{array}{c}1-2-6-7-9- \\
10-15-20\end{array}$ & 25.5 & $\begin{array}{c}23 \cdot 37 \\
5\end{array}$ & $\begin{array}{c}29.7 \\
5\end{array}$ & 19 & 13.65 \\
\hline
\end{tabular}

Table 6 showed the ranking of 10 possible paths after applying the weighted product method by combining multiple criteria into a cost value.

Table 6: Overall ranking for different time with consideration of two criteria by APPA

\begin{tabular}{|c|c|c|c|c|}
\hline \multirow{3}{*}{ Routes } & \multicolumn{4}{|c|}{ Ranking with consideration of two criteria } \\
& Mornin & Afternoo & Evenin & Midnigh \\
& $\mathrm{g}$ & $\mathrm{n}$ & $\mathrm{g}$ & $\mathrm{t}$ \\
\cline { 2 - 5 } & \multicolumn{4}{|c|}{ Time Travel + Distance } \\
\cline { 2 - 5 } & \multicolumn{4}{|c|}{ Ranking } \\
\hline $1-2-6-12-$ & 3 & 1 & 1 & 2 \\
\hline
\end{tabular}




\begin{tabular}{|c|c|c|c|c|}
\hline $19-20$ & & & & \\
\hline $\begin{array}{c}1-2-6-12-11- \\
15-20\end{array}$ & 4 & 3 & 3 & 3 \\
\hline $\begin{array}{c}1-2-4-7-6- \\
12-19-20\end{array}$ & 10 & 10 & 10 & 10 \\
\hline $\begin{array}{c}1-2-4-7-9- \\
10-15-20\end{array}$ & 5 & 6 & 5 & 5 \\
\hline $\begin{array}{c}1-3-5-8-9- \\
10-15-20\end{array}$ & 2 & 4 & 4 & 4 \\
\hline $\begin{array}{c}1-3-4-2-6- \\
12-19-20\end{array}$ & 9 & 9 & 9 & 9 \\
\hline $\begin{array}{l}1-3-4-7-6- \\
12-19-20\end{array}$ & 8 & 8 & 8 & 8 \\
\hline $\begin{array}{c}1-3-4-7-9- \\
10-15-20\end{array}$ & 1 & 2 & 2 & 1 \\
\hline $\begin{array}{c}1-2-6-12-11- \\
10-15-20\end{array}$ & 6 & 5 & 6 & 6 \\
\hline $\begin{array}{l}1-2-6-7-9- \\
10-15-20\end{array}$ & 7 & 7 & 7 & 7 \\
\hline
\end{tabular}

The blue highlighted was the first rank of different time period. The path $1 \rightarrow 2 \rightarrow 6 \rightarrow 12 \rightarrow 19 \rightarrow 20$ was the first rank for Afternoon and Evening period with the lowest cost values in term of distance and time travel. Besides, path $1 \rightarrow$ $3 \rightarrow 4 \rightarrow 7 \rightarrow 9 \rightarrow 10 \rightarrow 15 \rightarrow 20$ was the best path with the first rank for Morning and Midnight period by APPA.WPDA identified that path $1 \rightarrow 3 \rightarrow 4 \rightarrow 7 \rightarrow 9 \rightarrow 10 \rightarrow 15 \rightarrow 20$ was the optimal path for Afternoon period but APPA ranked path $1 \rightarrow 2 \rightarrow 6 \rightarrow 12 \rightarrow 19 \rightarrow 20$ as the first choice of optimal path. The difference of cost values between path $1 \rightarrow 2 \rightarrow$ $6 \rightarrow 12 \rightarrow 19 \rightarrow 20$, and $1 \rightarrow 3 \rightarrow 4 \rightarrow 7 \rightarrow 9 \rightarrow 10 \rightarrow 15 \rightarrow 20$ was about 0.04864 from Table 6 . The possible decimal problem caused a slight difference between rankings of two alternatives that have slightly identical in terms of cost values. Overall, WPDA and APPA can produce identical results. APPA might consume some time in computing the total cost values by calculating all the values for the paths one by one. The results of the combination between Weighted Product Method (WPM) and Dijkstra's algorithm in this study are of similar concept as proposed by Roghanian \& Shakeri Kebria (2017).

\section{CONCLUSION}

In conclusion, Weighted Product-Dijkstra Algorithm (WPDA) performed better than All Possible Path Algorithm
(APPA) in terms of simplicity and shorter computational time. The main contribution of this study is to find out a similar method in dealing multi dimension problem with multi criteria. WPDA can identify the optimal path directly with consideration of multiple criteria instead of just a single criterion by the Dijkstra's algorithm. When WPDA is compared with APPA, WPDA can directly identify the optimal path without the involvement of all the possible paths. APPA can provide the ranking of all the possible paths, but it has to consider of the entire possible paths. Overall, WPDA can be a desirable method for road users who need the ideal path with consideration of more than a single criterion. On the other hand, APPA can be useful for users who need to have alternate choices of road paths, such as applicable for tourists, tour guides and ambulance services.

\section{ACKNOWLEDGEMENT}

The authors would like to thank Universiti Malaysia Sabah for funding this research under the grant code GUGo1391/2017 and the contributions of the Sabah Road Transport and Safety Department for giving their statistics in this study. 


\section{REFERENCES}

Neumann, T. 2014, Method of Path Selection in the GraphCase Study. International Journal on Marine Navigation and Safety of Sea Transportation, 8(4):557-562.

Setyawan, A., Arini, F. Y. \& Akhlis, I. 2017, Comparative Analysis of Simple Additive Weighting Method and Weighted Product Method to New Employee Recruitment Decision Support System (DSS) at PT. Warta Media Nusantara.Scientific Journal of Informatics, 4(1): 34-42.

Fitriasari, N. S., Fitriani, S. A., \& Sukamto, R. A. 2017, Comparison of Weighted Product Method and Technique for Order Preference by Similarity to Ideal Solution Method: Complexity and Accuracy. In Science in Information Technology (ICSITech), 2017 3rd International Conference on (pp. 453-458).

Mateo, J. R. S. C. 2012, Weighted Sum Method and Weighted Product Method. In Multi Criteria Analysis in the Renewable Energy Industry (pp. 19-22). Springer, London.

Gayatri, S. V. \&Chetan, S. M. 2013, Comparative Study of Different Multi-Criteria Decision-Making Methods. International Journal of Advanced Computer Theory and Engineering (IJACTE), 2(4):9-12.

Odu G. O. \& Charles-Owaba O. E. 2013, Review of MultiCriteria Optimization Methods-Theory and Applications. International organization of Scientific Research Journal of Engineering (IOSRJEN), 3(10):1-14.

Tofallis, C. 2014, Add or multiply? A Tutorial on Ranking and Choosing with Multiple Criteria. INFORMS Transactions on Education, 14(3):109-119.

Nagar, A. \&Tawfik, H. 2007, A Multi-Criteria Based Approach to Prototyping Urban Road Networks. Issues in Informing Science \& Information Technology, 4:749756.

Roghanian, E. \& Shakeri Kebria, Z. 2017 The Combination of TOPSIS Method and Dijkstra's Algorithm in Multi-Attribute Routing. Scientia Iranica, 24(5):2540-2549.

Mohammadi, E., \& Hunter, A. 2012, Multi-Criteria Path Finding. ISPRS-International Archives of the Photogrammetry, Remote Sensing and Spatial Information Sciences, 1:157-159.

Bose, S. K. 2012, Operations Research Methods. Alpha Science International Ltd. Oxford, U.K.
Kolios, A., Mytilinou, V., Lozano-Minguez, E., \& Salonitis, K. (2016). A comparative study of multiple-criteria decision-making methods under stochastic inputs. Energies, 9(7): 566. 